\title{
Molecular analysis of paranasal fungus ball in Japan using formalin-fixed paraffin-embedded (FFPE) sections
}

\author{
Megumi Wakayama, Minoru Shinozaki, Naobumi Tochigi, Souta Sadamoto, Yasuhiro \\ Nihon-yanagi, Aki Mitsuda, Somay Y Murayama, Tetsuo Nemoto, and Kazutoshi Shibuya \\ Department of Surgical Pathology, Toho University School of Medicine
}

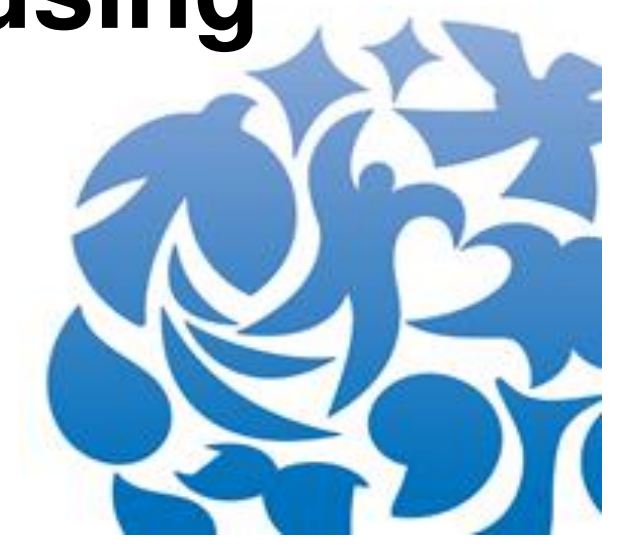

\section{CONCLUSION}

PCR technique using FFPE sections was useful for retrospective study to know causative fungi of fungal sinusitis, even in cases which had negative result by culture.

In present study, Aspergillus spp. were supposed to be the most common causative fungi of the disease. Whereas concern of contamination should be excluded, it is suggested that Basidiomycota is one of considerable causative fungi of non-invasive fugal sinusitis in Japan.

OBJECTIVE
Non-invasive fungal sinusitis, forming
fungus balls in paranasal cavities, is the
most common type of the fungal
sinusitis. The fungus balls are
composed by filamentous fungi mostly,
but they may not be identified by culture
in many cases. And it is difficult to
accurately distinguish between
Aspergillus spp. and other filamentous
fungi by Grocott's methenamine silver
staining. So we conducted fugus ball
using molecular identification to know
the epidemiology of non-invasive fungal
sinusitis.

\section{MATERIAL AND METHODS}

It was extracted 72 specimens of formalin-fixed paraffin-embedded (FFPE) sections of fungus ball removed from paranasal sinuses at Toho University Omori Medical Center in Tokyo, from 2002 to 2016 . All 72 were diagnosed as fungal sinusitis of filamentous fungi by histopathological examination. DNA was detected using a conventional polymerase chain reaction (PCR) method using panfungal primer targeting the 18S/ITS1 rRNA gene, and Aspergillus primer targeting the $28 \mathrm{~S}$ rRNA gene. And the resulting amplification products were prepared for sequence analysis and BLAST analysis.

\section{DISCUSSION}

PCR technique using FFPE sections enabled retrospective study of causative fungi of fungal sinusitis, even in specimens which had negative by culture. But fragmentation of DNA by formalin-fixation often affects PCR results. In present study, $33 / 72(45.8 \%)$ and $31 / 72(43.1 \%)$ were negative for PCR analysis by each primer.

Aspergillus spp., especially $A$. flavus and $A$. fumigatus, were the commonest fungi involving paransal sinus. $39 / 72(54.2 \%)$ were supposed to be Aspergillus spp. by panfungal and/or Aspergillus primer.

And 11/72 (15.3\%) showed genes of Basidiomycota, that may support the data that fungal sinusitis caused by Basidiomycota had been reported frequently because of the humid atmosphere in Japan. But the histological findings of fungi and the PCR results are not always equal. So contamination by environmental fungi or other organisms must be the large problem of PCR tequnique.

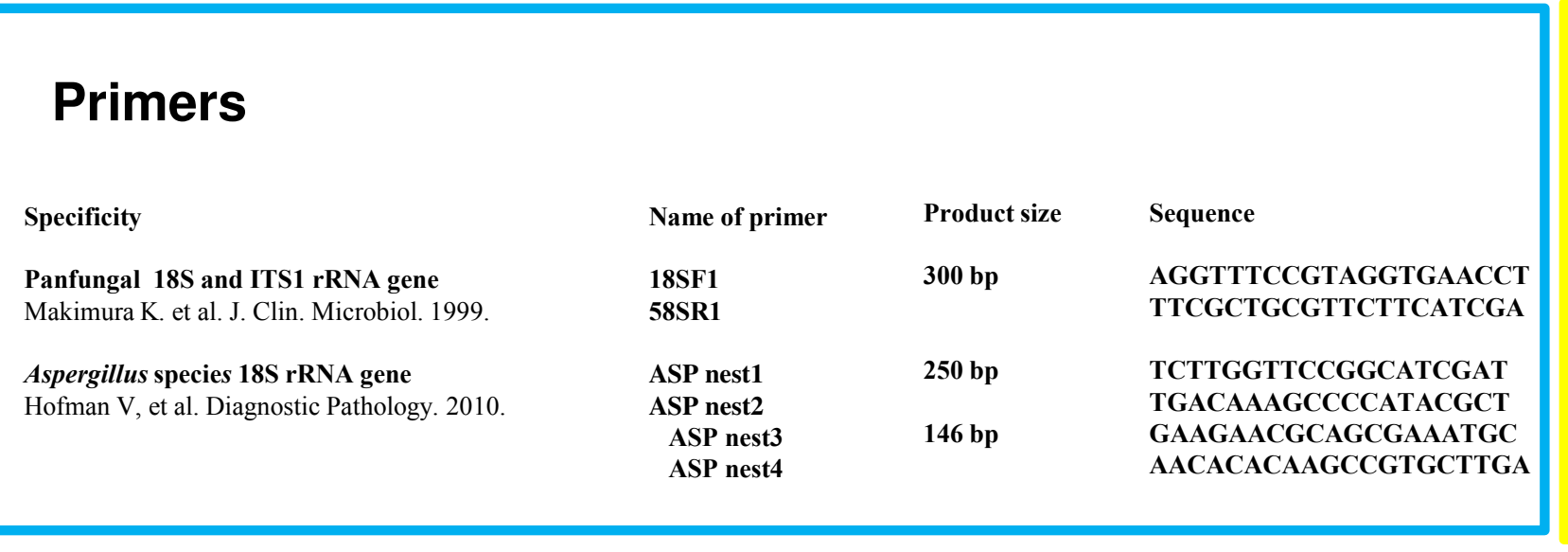

PCR results of the 72 specimens

\begin{tabular}{|c|c|c|}
\hline \multicolumn{3}{|c|}{ Panfungal primer } \\
\hline Positive & 39 & $(54.2 \%)$ \\
\hline Negative & 33 & $(45.8 \%)$ \\
\hline \multicolumn{3}{|c|}{$\underline{\text { Aspergillus primer }}$} \\
\hline Positive & 41 & $(56.9 \%)$ \\
\hline Negative & 31 & $(43.1 \%)$ \\
\hline
\end{tabular}

BLAST results of the 72 samples (1) (Panfungal primer)

Aspergillus spp. Mushrooms (Basidiomycota) Cladosporium spp. Malassezia restrict Candida rugosa Not identified
BLAST results of the 72 samples (2) (Aspergillus primer)

Number of specimens

$\begin{array}{lrr} & \\ \text { Aspergillus sp.or Penicillium sp. } & 15 & 20.8 \% \\ \text { Aspergillus flavus } & 10 & 13.9 \% \\ \text { Aspergillus fumigatus } & 6 & 8.3 \% \\ \text { Aspergillus sp. } & 6 & 8.3 \% \\ \text { Penicillium sp. } & 2 & 2.8 \% \\ \text { Malassezia sp. } & 1 & 1.4 \% \\ \text { Mycobacterium sp. } & 1 & 1.4 \% \\ & & \\ \text { Not identified } & 31 & 43.1 \%\end{array}$

\section{Case 40 BLAST results: Aspergillus flavus}

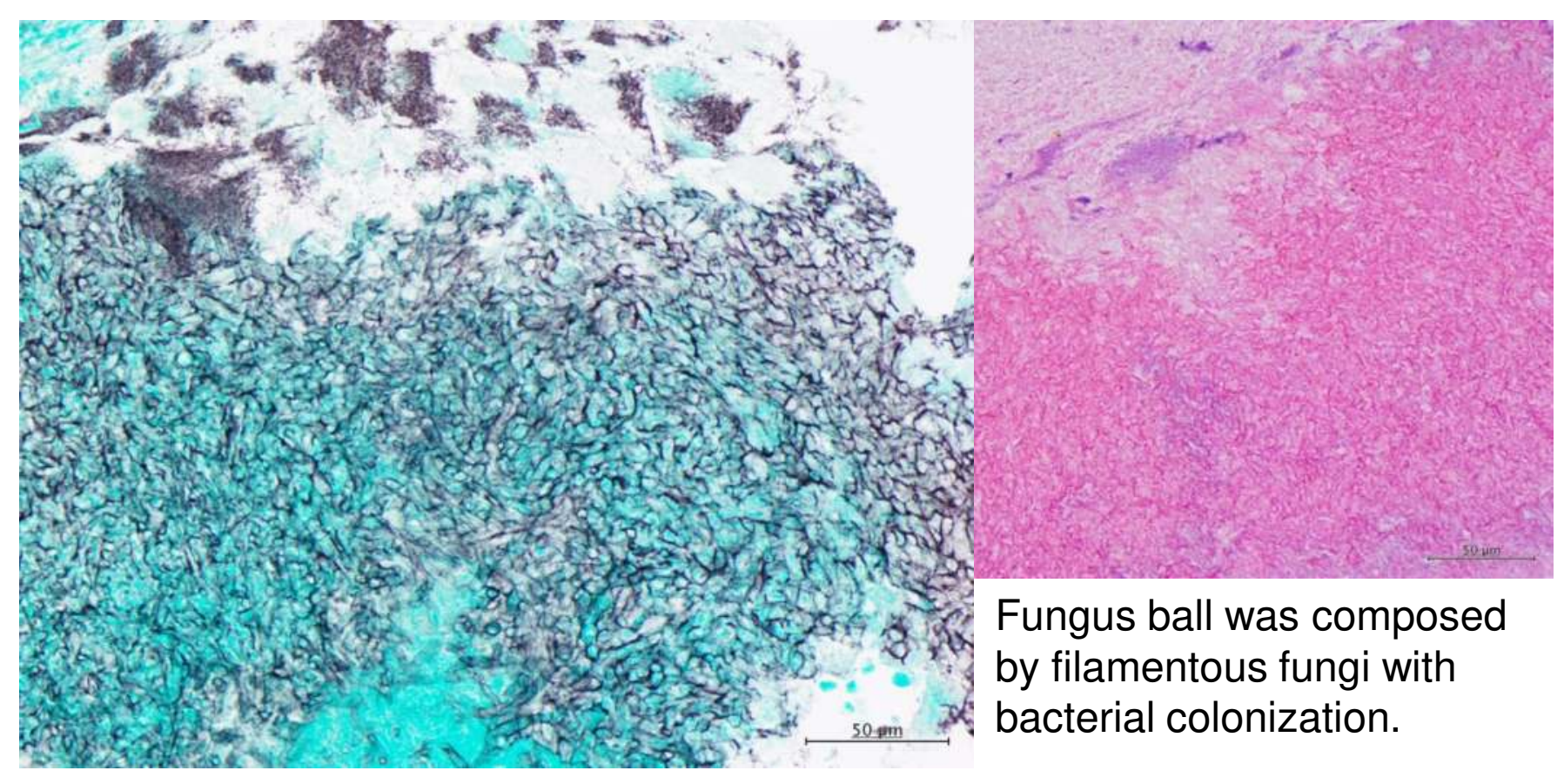

\section{Case 41 BLAST result: Schizophyllum commune}

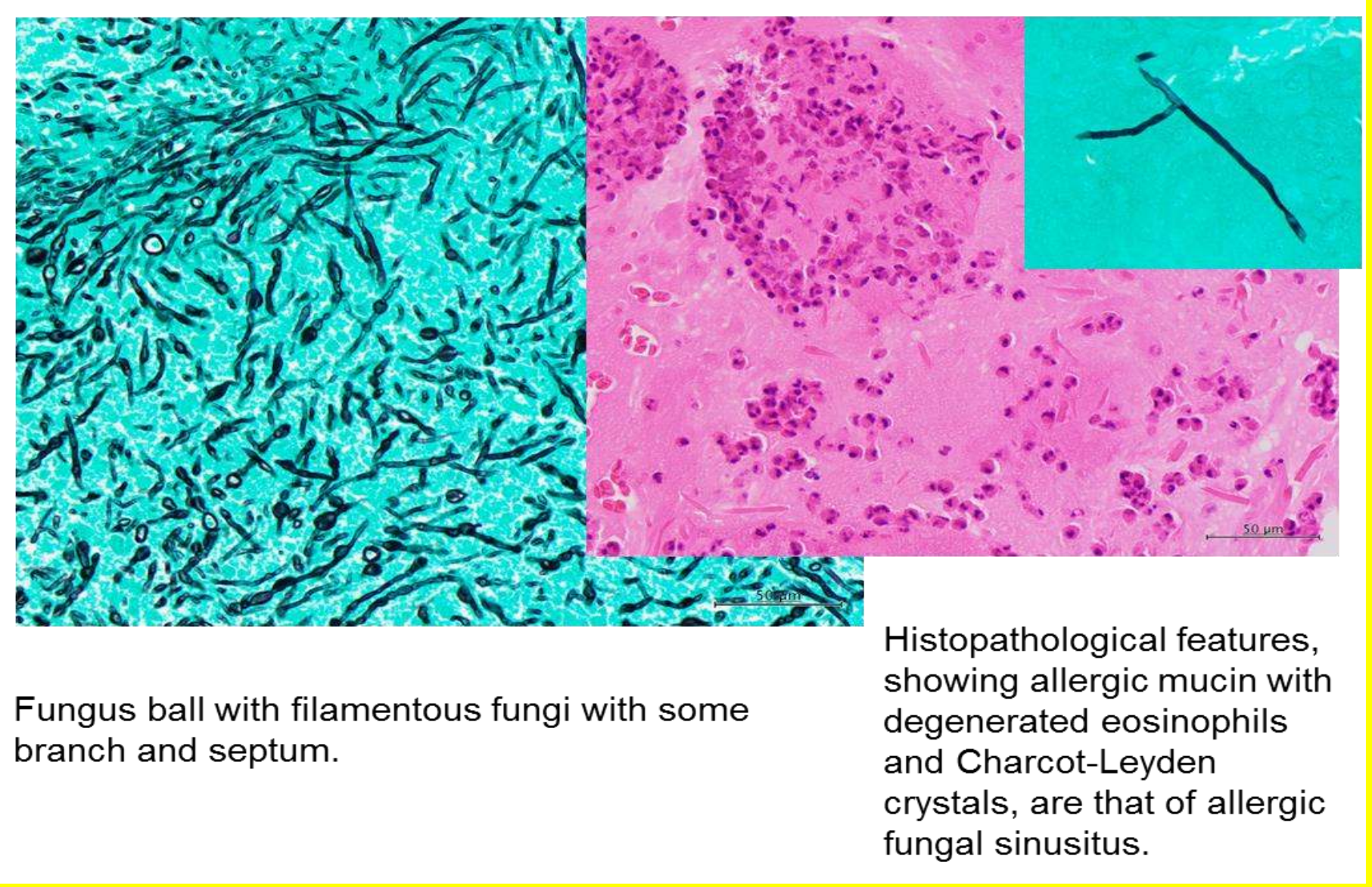

